1975

\title{
Experimenting on Human Subjects: Philosophical Perspectives
}

Ruth Macklin

Susan Sherwin

Follow this and additional works at: https://scholarlycommons.law.case.edu/caselrev

Part of the Law Commons

\section{Recommended Citation}

Ruth Macklin and Susan Sherwin, Experimenting on Human Subjects: Philosophical Perspectives, 25 Case W. Rsrv. L. Rev. 434 (1975)

Available at: https://scholarlycommons.law.case.edu/caselrev/vol25/iss3/4

This Symposium is brought to you for free and open access by the Student Journals at Case Western Reserve University School of Law Scholarly Commons. It has been accepted for inclusion in Case Western Reserve Law Review by an authorized administrator of Case Western Reserve University School of Law Scholarly Commons. 


\title{
Experimenting on Human Subjects: Philosophical Perspectives*
}

\author{
Ruith Macklin $\dagger$ \\ and \\ Susan Sherwin
}

\begin{abstract}
The ethical problems that attend the use of human subjects present difficult questions both for researchers and for society. The authors investigate these issues from various philosophical points of view, focusing on the theories of Immanuel Kant and John Stuart Mill. After exploring the shortcomings of these theories as guides for resolving the ethical questions inherent in human experimentation, the authors suggest John Rawls theory of social justice as a model for making ethical judgments.
\end{abstract}

\section{INTRODUCTION}

THE USE OF human beings in scientific research raises fundamental issues that lie at the heart of philosophical inquiry. The first question that arises concerning experimentation on human subjects is: Why are we disturbed at all by such experimentation? Put more precisely, why do questions arise about experimentation on human beings when there are no similar questions concerning experimentation on inanimate objects? This general question is the basis for the more specific questions to which the analysis in this paper will be addressed.

There is, of course, an obvious and, indeed, trivial answer to the broader question: Human beings are persons, and persons should be treated differently from things, or inanimate objects. This obvious answer is one that we all accept and that we presuppose in

* Supported in part by the National Endowment for the Humanities under Grant No. EH-6028-111, and under the auspices of the Moral Problems in Medicine Project at Case Western Reserve University. The contents of this article do not necessarily represent the view of the Endowment.

$\dagger$ Associate Professor of Philosophy, Case Western Reserve University. B.A., Cornell University, 1958; M.A., Case Western Reserve University, 1966; Ph.D., 1968.

$\mp$ Assistant Professor of Philosophy, Dalhousie University (Halifax, Nova Scotia). B.A., York University (Toronto), 1969; Ph.D., Stanford University, 1974. 
our worries about experimenting on human subjects. However, the deeper, philosophical answer to the basic question constitutes an explication and justification of the claim asserted in the trivial response. We want to know the nature of persons, the centrally important characteristics $^{1}$ of human beings, which make them different from inanimate objects in a way that is relevant to how human beings ought to be treated. The answer to this question requires that we explore some territory that lies at the intersection of the two following philosophical areas: philosophy of mind and ethics.

Before turning to a brief look at the cluster of general questions in philosophy of mind and ethics which relate to the nature of persons and how human beings ought to be treated, it would be well to identify the two specific questions on which this paper will focus: (1) What kinds of experiments on human beings can be morally justified? and (2) Under what constraints should experimental subjects be selected or allowed to participate? In a philosophical examination of these questions, it is necessary to note several specific concepts that are prominent in the area in which ethics and philosophy of mind intersect and that bear crucially on the sorts of values we must identify and explore. These concepts include the presumed rationality and autonomy of persons as well as the notions of voluntariness, coercion, and paternalism. All of the concepts bear on the central moral values in our view of human beings: that since persons have an intrinsic worth and an inherent dignity, they ought to be treated with respect. Not surprisingly, these concepts and values cluster around the debates and dilemmas relating to "informed consent," a preeminent concern in human experimentation. ${ }^{2}$ The discussion in this paper will focus on the specific application of these concepts to the problems surrounding human experimentation and look briefly at some of the philosophical underpinnings.

1. Sometimes what we refer to here as "centrally important characteristics" are termed "essential properties" or the "essence" of human beings. In such accounts, notably those of Plato and Aristotle, all things-including persons-are assumed to have an essence, or that which makes them the kind of thing they are. Many modern accounts, especially those of existentialist philosophers, deny that man has an essence. We want to be neutral concerning these essentialist or antiessentialist metaphysical positions, and so we hope that our terminology is acceptable to anyone who has any views whatever on this subject. All we intend in referring to "centrally important characteristics" is that set of attributes or properties, possessed by humans, which leads to our having moral rules, ethical beliefs, systems of reward and punishment, or anything else presupposing human responsibility for human actions.

2. See Cowan, Human Experimentation: The Review Process in Practice, 25 CASE W. RES. L. REV. 533, 536-37 (1974). 


\section{The PhILOSOPhICAL BaCKGround}

Among other things, philosophy of mind is an inquiry into the nature of persons. What, if anything, is unique or special about persons? How do their characteristics, abilities, structure, and function differ from those of other entities that we categorize as things, machines, or instruments? Unless we can begin to formulate an answer to this type of question, we cannot move to the basic ethical questions which this paper addresses. In attempting to spell out the answer to the inquiry in philosophy of mind, we will construct a framework for an ethical theory that offers moral principles for how we ought to treat people or what sorts of actions are morally permissible. It is not sufficient for an ethical theory merely to assert such principles, but it also must offer a justification for them. Moral philosophy is not casuistry, a study of cases of conscience in an attempt to give specific solutions to problematic ethical dilemmas. Instead, philosophical ethics seeks to offer general moral principles and a thorough justification for their adoption and application in a wide variety of situations in which any person might find himself. This presupposes at least a provisional account of the nature of persons.

A further word about moral philosophy is in order. Unlike specific ethical codes of behavior or even ethical prescriptions or commandments that derive from religious sources, philosophical ethical theories generally avoid dogmatic principles or rigid, exceptionless commands. One purpose of a sound philosophical ethics is to mediate between an unjustified dogmatism, on the one hand, and an unwarranted moral skepticism on the other. Hence, philosophical ethics places a premium on the giving of reasons, both in support of the moral principles themselves and against the competing claims of dogmatic ethics and moral skepticism. Moreover, as we shall try to show in the account that follows, the fundamental moral principles of the most prominent ethical theories can serve as a basis for addressing the specific issues that arise in connection with experimentation on human subjects.

We return now to a closer look at the general question posed at the outset: What are the centrally important characteristics of human beings, which render them different from inanimate objects in a way that is relevant to how human beings ought to be treated? After laying the groundwork through inquiry into this question-including a brief look at two prominent ethical theories-we shall be prepared to discuss the ethically relevant criteria for answering the 
two specific questions pertinent to human experimentation: (1) What kinds of experiments can be justified? and (2) Under what constraints should subjects be selected or allowed to participate?

The first human characteristic relevant to our concerns here is that of sentience. Human beings, like other higher forms of animal life, are sentient creatures; that is, they are capable of feeling pleasure and pain under a wide range of predictable circumstances. What is more, people pursue pleasure and seek to avoid pain. Some philosophers and psychologists have gone so far as to claim that pursuit of pleasure and avoidance of pain are the sole factors motivating human behavior. ${ }^{3}$ We need not go this far, however, in order to acknowledge the primacy of pain and pleasure as determinants of human action. It is this basic fact of sentience, conjoined with the teleological principle that people seek pleasurable ends and avoid actions with painful or unpleasant consequences, that has led to the widespread acceptance of one prominent ethical theory, utilitarianism.

One of the leading utilitarians, the 19th century English philosopher, John Stuart Mill, argued that pleasure is the sole thing that is good as an end. Since each person takes his own pleasure or happiness to be his ultimate aim or goal, toward which all particular activities are a means, Mill claimed that the value that should be maximized in the community as a whole is the greatest happiness of all. For the most part, Mill followed his utilitarian predecessor, Jeremy Bentham, in adopting the "Greatest Happiness Principle" as the fundamental moral principle of his ethical theory. ${ }^{4}$

3. Such a view may be found in the words of Jeremy Bentham:

Nature has placed mankind under the governance of two sovereign masters, pain and pleasure. It is for them alone to point out what we ought to do, as well as to determine what we shall do. On the one hand the standard of right and wrong, on the other the chain of causes and effects, are fastened to their throne.

Bentham, An Introduction to the Principles of Morals and Legislation, in Problems of Moral PhILOSOPhy 151 (2d ed. P. Taylor 1972).

Freud expressed a similar view:

The sovereign tendency obeyed by these primary processes is easy of recognition; it is called the pleasure-pain (Lust-Unlust) principle, or more shortly the pleasure-principle. These processes strive towards gaining pleasure; from any operation which might arouse unpleasantness ("pain") mental activity draws back (repression).

S. FREUd, Formulation Regarding the Two Principles in Mental Functioning, in General Psychological Theory 22 (reissued 1963).

4. Mill writes, "the principle of utility, or, as Bentham latteriy called it, the greatest happiness principle, has had a large share in forming the moral doctrines even of those who most scornfully reject its authority." J.S. MILL, UTILITARIANISM 6 (Bobbs-Merrill 1957). 
As Mill himself stated, under the principle of utility, "actions are right in proportion as they tend to promote happiness; wrong as they tend to produce the reverse of happiness. By happiness is intended pleasure and the absence of pain; by unhappiness, pain and the privation of pleasure."5 In order to prevent any misunderstanding of this influential theory, a bit more needs to be said by way of explication and interpretation of the utilitarian moral principle.

First, it should be emphasized that Mill explicitly disavows the interpretation of his theory as a "gross form" of hedonism. " While he clearly identifies happiness and pleasure, as shown in the abovequoted statement of the utilitarian principle, Mill nevertheless argues for a qualitative distinction among pleasures in addition to the usual distinction in terms of quantity or amount-the view held by Bentham and others. Mill writes:

It is quite compatible with the principle of utility to recognize the fact that some kinds of pleasure are more desirable and more valuable than others. It would be absurd that, while in estimating all other things quality is considered as well as quantity, the estimation of pleasure should be supposed to depend on quantity alone.?

Thus, although Mill does identify happiness and pleasure, he argues against the mistake of confounding "the two very different ideas of happiness and content."8 These so-called "higher pleasures" include the pleasures of the intellect, of the feelings and imagination, and of the moral sentiments-all of which are to be accorded a higher value as pleasures than those of "mere sensation."

A second, related point should also be stressed in explicating Mill's view. Utilitarianism might be criticized as being a crass, majority-rule doctrine, in which a preference for any action or state of affairs whatsoever of 51 percent of the population renders that action or state of affairs morally acceptable. This criticism rests on a misinterpretation of the intent of the utilitarian moral position. Throughout his essay, and especially in the lengthy final chapter entitled "On the Connection Between Justice and Utility," Mill expresses concern for minority rights and, indeed, the basic rights of persons. The claimed weakness of the utilitarian position lies in Mill's response to an objector who asks why society ought to defend
5. Id. at 10 .
6. Id. at 9 .
7. $I d$. at 12 .
8. Id. at 13 . 
a person in the possession of his rights; Mill replies: "I can give him no other reason than general utility." Although nonutilitarians such as Immanuel Kant and John Rawls ${ }^{10}$ have found Mill's answer unsatisfactory, a careful reading of Mill's writings reveals a pervasive humane and humanitarian thread woven throughout. A serious problem remains, however, in that the principle of utility alone -as a fundamental moral principle-does not seem able to account for a variety of ethical duties and precepts of justice without the additional corollaries and interpretive remarks offered by Mill and other defenders of utilitarianism.

In summary, we should emphasize again that utilitarians claim that their ethical theory is derivable from certain indisputable facts about human beings-sentience and the tendency of persons to seek pleasure or happiness and avoid pain or unhappiness. It is clear that the utilitarian principle often provides the basis for how people actually make judgments about the rightness and wrongness of actions. As we shall see below, this ethical principle is frequently the operative criterion that guides many decisions in specific cases of experimentation on humans. In particular, it seems that utility is the underlying moral principle in the notion of the "riskbenefit" equation, about which more will be said later. ${ }^{11}$

We now turn to the second basic characteristic of human beings, with which another prominent ethical theory is closely associated. This attribute of the human species is rationality, and one major ethical theory that arises largely out of this human characteristic is the doctrine of the 18th century German philosopher, Immanuel Kant. Closely linked with the concept of rationality is that of personal autonomy, to which ethical values are attached. Kant's ethical system begins by presupposing rationality and autonomy as fundamental characteristics of persons. He then constructs a moral theory that is applicable to all rational beings, who possess what he describes as an autonomous, self-legislating will. The inherent autonomy of each person, which is produced by his rationality, requires that each person be treated as a creature having dignity and, therefore, worthy of respect. In Kant's view, rationality and autonomy are the essential humanity-conferring properties and give rise to the moral principle that persons should be accorded dignity and treated with respect.

9. Id. at 66 .

10. See Kant, Fundamental Principles of the Metaphysics of Morals, in Problems of Moral PhIIOSOPhy 236-37 (2d ed. P. Taylor 1972); J. RaWLs, A THEORY OF JUSTICE 209-11 (1971).

11. Text accompanying note 37 infra. 
Kant used the term rationality to apply to an attribute of the human species rather than to an attribute of individual persons. As a result, the Kantian framework does not give us a criterion for distinguishing between rational individuals and irrational or nonrational individuals. Instead, it treats the human species (or any other "higher" beings) as having the capacity to reason and form concepts and, hence, as possessing the attribute of rationality. Some further distinctions and an explication of several specifiable senses of rational will be offered in section III, below. We hope to show that each of these different senses of rational is a key concept in problems relating to informed consent in special groups of experimental subjects: young children and the aged, the mentally retarded, the so-called "mentally ill," and prisoners. What is required at this point is a brief account of the way in which the concept of rationality and that of autonomy are linked in Kant's theory. We may then see how the human characteristic of rationality gives rise to some fundamental ethical values and moral principles.

Kant's notion of morality is that "its law must be valid, not merely for men, but for all rational creatures generally, not merely under certain contingent conditions or with exceptions, but with absolute necessity . . ."12 This passage makes explicit Kant's concept of morality as one that is applicable to all rational beings rather than one whose application is designed specifically for humans; it also exhibits the tone of his moral philosophy, which has led many to object that it is an implausibly rigid ethical system, since its law commands "with absolute necessity." On the basis of this notion of the nature and scope of morality, Kant formulates his account of the derivation of the commands of ethics:

[S]ince moral laws ought to hold good for every rational creature, we must derive them from the general concept of a rational being. ... .

Everything in nature works according to laws. Rational beings alone have the faculty of acting according to the conception of laws, that is according to principles, i.e. have a will. Since the deduction of aotions from principles requires reason, the will is nothing but practical reason. ${ }^{13}$

Kant terms the fundamental moral principle or law of morality "the categorical imperative," ${ }^{14}$ since the moral law commands ab-

12. Id. at 222 .

13. Id. at 223-24.

14. Id. at 228. 
solutely (categorically) rather than conditionally (hypothetically).

In the archaic language in which Kant himself expresses it, the categorical imperative states: "Act only on that maxim whereby thou canst at the same time will that it should become a universal law."15 Kant argues that all imperatives of duty can be deduced from this one fundamental principle, since persons can always formulate a maxim for each act they consider performing and then test the maxim for conformity to the fundamental principle, or categorical imperative. If the maxim passes the test, that is, if it can consistently be willed by the agent as a universal law, applicable to all rational creatures, then the contemplated action is morally permissible or morally right. We should emphasize here that this is a purely formal requirement for Kant, a necessary condition for an imperative to count as a moral law. The test Kant postulates is generally referred to, in an alternative formulation, as the requirement of generalization, or universalizability, in ethics. The core idea in all these views is that a moral law is one that holds for all persons similar in relevant respects in all like circumstances. Thus, what is right for one would be right for all similar persons in similar circumstances. Moreover, for a maxim to pass the test of the categorical imperative, it is not a matter of whether or not the agent can will the maxim to be a universal law as a matter of psychological fact. It is, rather, a question of logical consistency: maxims that cannot be willed to be universal laws, as prescribed by the categorical imperative, fail either because they lead to a logical contradiction or because such a will would contradict itself. A good will formulates and acts only on those maxims that prescribe our duties; morally right acts are those done for the sake of duty. So, for example, if a person contemplated breaking a promise when it was inconvenient for him to keep it, he would have to formulate a maxim of the following form: it is morally permissible to break promises when it is inconvenient to keep them. This maxim cannot (consistently) be universalized, since if everyone acted in accordance with it, the social institution of promising would soon break down, and there would no longer be a meaningful concept of a promise.

There is but one categorical imperative according to Kant, and yet he offers what he terms a second formulation of this fundamental principle: "So act as to treat humanity, whether in thine own person or in that of any other, in every case as an end withal, never 
as means only."16 It is not our concern here to debate the question whether or not this statement is another formulation of the same principle or a new principle based on additional assumptions; we leave that debate to. Kantian scholars. The second formulation succeeds in capturing a common moral sentiment: we ought to treat our fellow human beings as ends in themselves and not as mere means or instruments for our own purposes, even to serve socalled "noble" aims. It is this second formulation of Kant's categorical imperative that seems especially appropriate as a moral principle applicable in cases of human experimentation, for we can always test proposed actions using human subjects against the principle that persons should be treated as ends, never as mere means. Kant claims that "[t] $[$ he foundation of this principle is: rational nature exists as an end in itself."17

Finally, Kant offers what he considers the third formulation of the categorical imperative, from which the notion of autonomy emerges. The "third practical principle of the will, which is the ultimate condition of its harmony with the universal practical reason [is] the idea of the will of every rational being as a universally legislative will."18 This capacity of every human will to be a universally legislating will is what constitutes the principle of autonomy of the will, which, according to Kant, is claimed to be "the basis of the dignity of human and of every rational nature."19 We can see, then, how the fundamental characteristic of rationality and the derivative concept of autonomy form the foundation for those values most central to our humane moral beliefs. From Kant's moral philosophy we obtain the important value conception of the intrinsic worth or dignity of human beings. In arguing for the central importance of duty in a conception of morality, Kant sums up these interrelationships as follows:

The practical necessity of acting on this principle, i.e. duty, does not rest at all on feelings, impulses, or inclinations, but solely on the relation of rational beings to one another, a relation in which the will of a rational being must always be regarded as legislative, since it otherwise could not be conceived as an end in itself. Reason then refers every maxim of the will, regarding it as legislating universally, to every other will and also to every action towards oneself; and this not on account of any other practical motive or

16. Id. at $234-35$.

17. Id. at 234 .

18. Id. at 236 .

19. Id. at 239 . 
any future advantage, but from the idea of the dignity of a rational being, obeying no law but that which he himself also gives. ${ }^{20}$

The ethical theories of Kant and Mill each propose a basic general principle, according to which any moral agent can test his contemplated actions to ascertain their moral rightness or wrongness. In Kant's system, the central moral notion is that of duty, and the intrinsic human values are autonomy and dignity, both derived from the essential human attribute of rationality. Mill bases his theory on the empirically ascertained attribute of sentience in persons along with the observable goal-directed behavior of human beings in their pursuit of pleasure or happiness and avoidance of pain and suffering. The basic conceptions of morality found in both Kant and Mill seem to be required for a full account of our common moral sentiments and beliefs. In addition, they both provide a general principle under which we can subsume particular actions or subordinate moral rules in order to test their moral acceptability or validity. One need not consider himself a hedonist in order to accept the utilitarian principle, nor need one adhere, in general, to a duty-oriented conception of ethics in order to acknowledge the importance of the categorical imperative (in any of the formulations Kant suggests).

\section{ETHICAL CONCEPTS}

Having laid the groundwork through a brief examination of two major normative theories in philosophical ethics, we turn next to an exploration of several subordinate concepts in ethics-concepts that relate directly to the moral problems surrounding human experimentation. Arising out of the facts of man's sentience and pursuit of his own happiness or welfare, and also out of the fundamental human attribute of rationality and the derived notions of autonomy and dignity, the subordinate ethical concepts relevant to experimenting on humans include coercion and paternalism, autonomy and dependency.

The concepts we are about to examine all converge on the central concern in human experimentation: the need to obtain the informed consent of the experimental subject. It is evident that only by obtaining informed consent can we be sure we are treating the experimental subject as an end, and not as mere means; neglecting to seek informed consent would indicate a deeper failure to recognize the autonomy and, hence, the humanity of the subject. All 
three formulations of Kant's categorical imperative are relevant to our understanding of why we deem informed consent an important prerequisite for any experimentation on human beings.

It is appropriate, however, to begin our inquiry with a further look at the concept of rationality, since that notion lies at the roots of Kant's ethical system and is also the recurrent issue in problems relating to special groups of experimental subjects (e.g., children, the retarded, the mentally ill). The concept of rationality is problematic, partly because it is not a purely descriptive concept but is itself a normative notion, and, more importantly, because the term rational has several related yet distinct senses. Perhaps the most fundamental sense is that in which the concept of rationality purports to distinguish one class of beings or entities from all other entities or creatures. In this way, man is defined as "the rational animal," and so rationality is seen as a distinctive or essential property of the human species. It is this sense of rationality that appears to be Kant's conception, providing the basis for his ethical system. It is not clear, however, whether this sense of the term applies only to the human species (and, if they exist, "higher" beings such as God and angels), although it is intended to apply to all persons, qua members of the human species. The scope of this sense of rational remains open, with conceptual arguments offered on behalf of considering highly advanced computers, robots of the future, and, perhaps, dolphins as rational entities. It is worth speculating about whether we would become gravely concerned about experimenting on dolphins (in a way different from our ordinary concerns about animals) if, as a result of empirical inquiry, conceptual decision, or both, we determined that dolphins were rational creatures. It appears that both the attributes of sentience and rationality are required to generate what we consider moral concern for existing entities, in the sense that requires our treating them with dignity and respect. Computers and present-day robots lack the property of sentience, so even if we were to ascribe rationality to them, this alone would not require that we treat them in accordance with moral principles (although we may nonetheless decide that they should be kept in good repair). There is an asymmetry, then, between the possession of rationality alone and the possession of sentience alone, in respect to our treatment of non-human entities. The possession of sentience alone is a criterion for our treating creatures with some moral concern, as shown by our behavior towards higher forms of animal life and by the laws and regulations governing the use of 
animals in experimental contexts. ${ }^{21}$ We propose to bypass a discussion of experimenting on animals here, noting simply that sentience alone introduces the propriety of moral attitudes and behavior. It remains an open question whether the existence of rationality alone would similarly entitle its possessor to moral treatment at the hands of human beings.

The sense of rationality as necessarily applying to all human creatures is not a helpful notion when we want to distinguish among human beings in respect of their rationality, for special purposes. These purposes may include a perceived need to interfere with the behavior of those persons who are deemed irrational, whether on their own behalf (i.e., paternalistically), or for the good of society (i.e., coercively). Whether persons lacking in rationality in a qualitative sense, may be treated in ways that are morally impermissible when performed on fully rational humans is a central question arising in the context of experimentation on human subjects. The socalled mentally ill, the retarded, young children, the senile aged-all these persons have been considered, at the very least, as lacking full-scale rationality, if not as wholly irrational.

We turn next to two related yet distinct senses of rational, which appear to constitute the usual criteria for distinguishing persons generally considered rational from those deemed irrational or nonrational. In one of its common meanings, the term rational denotes the capacity of humans to use their reason (rationality) to maximize their chosen or accepted ends. This is the sense in which a rational person can defer the temptation of short range gain or pleasure for the sake of a longer term goal that he holds to be more important. Such a sense of rationality also encompasses the conception of a rational person as one who is good at calculation and inductive as well as deductive reasoning, since these are necessary attributes for consistently being able to choose the best means to one's ends. The other closely related sense of rational refers to the chosen ends themselves. In this sense of the term, the chosen means, if any, are not a criterion for ascribing rationality to the agent; it is, rather, the ends themselves that confer rationality. Self-destructive ends, painful or unprofitable goals, apparently pointless acts-all these are characteristic of the irrational, as the correlative notion. Thus, persons who attempt suicide are considered irrational by psychiatrists and others, and, as a result, are subjected to coercive measures

21. E.g., Laboratory Animal Welfare Act, 7 U.S.C. $\$ \S 2131-55$ (1970); 9 C.F.R. $\$ \$ 3.1-.114$ (1973). 
such as involuntary hospitalization. It is evident that the foregoing senses of the term irrational are different, since a person may be rational in one of these senses and irrational according to the other. ${ }^{22}$ Nevertheless, these two senses of rational and irrational enter prominently into ethical considerations in experimenting on humans.

One major concern in human experimentation is the question of the competence of persons to give their consent. The relevant meaning of competence here encompasses both of the senses of rational discussed immediately above. While it is patently clear that infants, the severely retarded, and wholly uncommunicative emotionally disturbed persons are not competent to give consent in any of the requisite senses of rational, the concepts in question fall along a continuum and may be difficult to apply in borderline cases. ${ }^{23}$ In approaching such problems, we should view the senses of rational and irrational either as enduring attributes of the persons to whom they apply or else as temporary attributes that cut across a wide range of abilities or capacities of a person. It is evident that infants, the severely retarded, or the emotionally disturbed lack the functional capacity, in general, for making intelligent decisions or rational choices, engaging in careful deliberations, or adopting prudent longrange ends or goals. Whether the class of persons lacks full-scale rationality or competence as an enduring attribute (e.g., the mentally retarded), or whether the irrational or non-rational status is temporary but pervades the whole personality (e.g., infants and "curable" mental patients), the above-noted concepts of rationality cut across most or all of a person's cognitive and deliberative abilities and capacities. There is, however, another use of the term irrational in which it applies only to a temporary and localized attribute of persons. Two sorts of examples serve to illustrate this use. First, there are cases in which a person might have temporary mood disturbances (e.g., depression) during which time he is not fully rational and may even contemplate suicide; most of the time, however, he can function adequately and well, even as a highly compe-

22. An example might be the person who "successfully" commits suicidewith efficiency and with the least financial and emotional cost to others.

23. It is generally held that lack of competence or rationality in a person warrants interference with his autonomy by others, in the belief that such interference is justified if it is necessary to the person's health or welfare. This sort of interference is central to the meaning of the concept of paternalisma concept that plays a key role in human experimentation when the experimental subjects themselves are unable to give informed consent. 
tent professional or academic. Secondly, there are cases in which a person might be suffering from temporary shock (e.g., after an accident) or profound grief (e.g., following the death of a loved one) or even extreme fear and anxiety (e.g., prior to difficult surgery on oneself or one's child). In both categories the competence of such persons may be called into question, even if the lack of rationality exhibited is temporary or confined to a small area of their total activities. Such an application of the notion of rationality enters prominently into judgments concerning informed consent: Under what circumstances can consent be considered fully informed, and who besides the experimental subject himself ought to be allowed to grant consent?

A word should be said about some of the epistemological issues pertaining to informed consent. While our primary focus in this article is on the ethical issues in experimentation on human subjects, philosophical problems of knowledge are relevant as well. The chief epistemological concern arises because the notion of "being informed" is none too clear. It is obvious that there are vastly different amounts of information that a person may possess, and, as a result, varying degrees of one's being informed. The question in the present connection is, how much information, and what specific sorts of information, ought a person have before his consent can properly be said to be informed?24 Some persons-usually, but not always, physicians ${ }^{25}$ - claim that a patient, or lay persons in general, can never be fully informed. In order for them to be, the argument runs, they would have to know as much as the physician knows about diseases, risks, complications, statistics about similar cases, and perhaps a range of other facts. If people had to know all these facts, theories, and statistics in order to be truly informed, consent could rarely be given even for most therapeutic procedures, much less for a variety of experiments employing human subjects. ${ }^{28}$ So, it is reasonable to look for some standard other than "full and com-

24. See Cowan, supra note 2, at 552-53, for a listing of the Department of Health, Education, and Welfare's criteria for informed consent.

25. E.g., Letter to the Editor from Nicholas J. Demy, M.D., 217 J.A.M.A. 696-97 (1971); Ingelfinger, Informed (But Uneducated) Consent, $287 \mathrm{NEw}$ ENG. J. MED. 465-66 (1972).

26. As Dr. Cowan notes, much the same problem exists on institutional review committees as a result of the medical ignorance of nonphysician members. See Cowan, supra note 2 , at 558. Ironically, it would seem that the nonphysician reviewer's ignorance might be the very factor that would best qualify him to appreciate just how informed the consent given by an equally ignorant subject is. 
plete information" on which to base consent. Just what such a standard should be remains a problem to be solved, but it is not insurmountable. Focus should probably be in the area of ascertaining what information is relevant for an experimental subject's consent to be sufficiently informed. While judgments about relevance are also subject to dispute, at least the problem becomes more manageable. An additional epistemological issue is the difficulty that the physician or experimenter faces in determining whether the experimental subject has the requisite understanding of the relevant information to grant his informed consent. ${ }^{27}$ Evidence is sometimes brought forth to show that even when patients or experimental subjects are given the necessary information, for a variety of possible reasons they may not adequately process or comprehend that information. So even when experimental subjects have been properly informed (told) by others about a proposed experiment, the subjects may nonetheless remain uninformed (lacking in understanding) in important ways.

Aside from these epistemological issues concerning what it is to be informed and how we can tell when a person really is informed in a particular case, there are the primary ethical difficulties relating to autonomy and dependency, paternalism and coercion. An analysis of the manner in which consent is obtained reveals how such ethical questions arise. Such an analysis requires an explication of the notion of voluntariness, in the sense that means "uncoerced actions." 28 In addition to being informed, consent must also be voluntary, or uncoerced, in order not to violate our moral principles prohibiting interference with other autonomous persons. It is precisely at this point that most of the moral problems are found concerning the use of prisoners as experimental subjects, and some of these same issues arise with other institutionalized populations,

27. This difficulty has prompted some institutional review committees to require that a family member witness the giving of consen't in order to further insure that the subject actually understood the full impact of his consent. Id. at 553-54.

28. There are other related meanings of the term "voluntary" besides the sense rendered here as "uncoerced." Especially in legal contexts, the notion of voluntariness may have a somewhat different application than the sense explicated in this article. Voluntariness is a somewhat problematic concept, and we do not intend to stipulate a definition; nor do we imply that the sense of the term that means "uncoerced" is the only or even the primary sense. Rather, we hope to capture the meaning that is central to the notion of a genuine volunteer: one who (voluntarily) offers himself for some purpose without being coerced. 
such as the aged or the terminally ill. ${ }^{29}$ Consent for research, therefore, must be voluntary and granted by mentally competent, rational agents who are properly informed.

For present purposes, we may identify several special classes of "dependent persons." These categories include children, ${ }^{30}$ mentally retarded persons, the aged, prisoners, and the mentally illespecially those emotionally disturbed persons who are institutionalized. The individuals comprising these classes of persons are functionally incapacitated or undeveloped in some way, and, therefore, tend to be viewed as less oapable of autonomous actions and decisions than are normal adults. While some of these individuals are dependent because of less-than-normal capacity to think or reason or make judgments (e.g., young children and mentally retarded persons), others, such as prisoners, are rendered dependent in special ways by the actions of society. The constraints placed on institutionalized persons constitute limitations on their freedom in ways that raise serious questions about their ability to grant fully voluntary consent to serve as experimental subjects. The ethical problems come to focus on the element of coercion that seems to be present on many occasions when informed consent is sought.

How can we tell when voluntariness is present? There are paradigm cases of coerced actions-those that are performed under threat of violence or some other negative sanction. If $I$ am accosted by someone with a gun who demands, "Your money or your life!" and I hand over my purse, do I do so voluntarily? In one sense, I do it voluntarily since I choose this alternative rather than the other, less desirable one. So, I voluntarily hand over my purse rather than risk death at the hands of the gunman. In another sense, this action does not seem wholly voluntary when compared with other cases in which I act not under threat of violence but willingly or "out of my own volition" or "of my own free will," as it is commonly put. In one perfectly ordinary way of speaking, I

29. An example of ethically suspect research on old persons who were hospitalized and terminally ill is the cancer study performed at the Jewish Chronic Disease Hospital in Brooklyn, New York. In this experiment, cancer cells were implanted in these patients, and it was charged that some of the experiments in this study were performed without the informed consent of the participants. For a full discussion, see ExPERIMENTATION wITH HuMAN BEINGs 9-66 (J. Katz ed. 1972).

30. For a discussion of some special problems associated with experimentation on children in connection with the development and testing of drugs, see Cowan, supra note 2 , at 556-57. 
hand over my purse to the gunman "against my will." There is, it appears, a problematic conceptual issue that needs to be addressed if we are to be able to assess when a person's decisions and actions are truly voluntary, in the sense of not coerced. We still have a problem of deciding what criteria to employ in judging when informed consent is truly voluntary and when a competent adult experimental subject is performing actions or making decisions under some form of coercion, however subtle. Critics of the use of prisoners (as well as other institutionalized persons) in research contend that the very role of prisoner precludes fully voluntary decision and action on the part of such individuals. ${ }^{31}$ This contention maintains that an element of coercion always exists in the very nature of the prisoner's role and in the constraints inherent in an institutionalized setting. We should be aware that debate on these issues rests only partly on moral considerations; much of the disagreement often lies in conceptual and factual matters, as well. For example, if the parties to a dispute about the morality of using prisoners in research could agree on whether prisoners can, in principle, ever volunteer in an uncoerced manner, or whether, on the contrary, their being prisoners entails an element of coercion in all behavior that involves prison officials and outsiders, they would come closer to settling the moral dilemma that lies at the heart of this issue.

Unlike prisoners, who are rendered dependent by the actions of society, other types of persons suffer reduced autonomy because of a natural dependence. The aged may suffer from impaired mental capacity, like retarded persons, and young children are not yet capable of autonomous decision and action. It is natural, and perhaps even necessary in many cases, to assume a protective attitude toward persons who are functionally incapacitated in some way. This attitude is exhibited, for example, in the phenomenon of "maternal instinct" in humans and other mammals. Dependent status makes the elderly and the retarded especially vulnerable to a variety of experimental treatments, only some of which might benefit them. ${ }^{32}$

31. See Lasagna, Special Subjects in Human Experimentation, 98 DAEDAlus 449-55 (1969); Mitford, Experiments Behind Bars, AtLantrc MonThLy, Jan. 1973, at 64,73 .

32. In the cancer study cited in note 29 supra, the researchers made no claims about possible benefits to the experimental subjects themselves. In contrast, the researchers who deliberately exposed retarded children at the Willowbrook State School to viral hepatitis defended their research on the grounds that these children would have contracted hepatitis even without this artificial 
When research is viewed as possibly or probably beneficial to the experimental subjects, it is justified on paternalistic grounds, namely: Interference is warranted because it will promote the welfare of the subjects themselves. Where no perceived benefit is possible or likely for the subjects themselves, an attempt to justify the interference cannot be based on paternalistic grounds. Rather, the experimenter must seek some other justification for treating persons as having less than full autonomy, that is, treating them in a coercive manner. People in institutions of any sort might be viewed as ideal subjects for experimentation because of the ease of observing them, the ability of researchers to select control groups, the opportunity for repetitive or long-term research using the same subjects, and so on. Unfortunately, however, these same institutionalized persons are often ideal subjects for another reason: their dependency and diminished human capacities render them easy prey to coercive measures of all sorts, including use in medical experiments by well-intentioned as well as unscrupulous researchers.

All of the moral issues in this broad area might be phrased in terms of the ethical notion of the rights of persons: What are the rights of children, retarded persons, and the mentally ill? In general, how ought persons who are functionally incapacitated be viewed with respect to the presence or absence of their human rights? What sorts of attributes must a person have-or lack-in order to retain basic human rights such as the right not to be interfered with or the right to be granted full-fledged freedom and autonomy? Who, if anyone, has the right to grant consent for experimentation on minor children, retarded persons, or the mentally ill? Conceiving the moral issues in terms of rights and duties is, however, only one way of placing them in an ethical perspective. Questions of the sort under discussion here do not seem to be made clearer or easier to answer by formulating them in terms of rights. Indeed, the ethical waters are often muddied by a variety of claims about people's rights that are difficult to substantiate. This is partly because of a range of problems associated with the notion of rights: Where do they come from? How do we know when they exist or in whom they reside? How do we settle conflicts of rights or disagreements about their existence or nonexistence in particular

exposure, but in the experimental setting the children would be "better off" since they would be under careful observation by the researchers and the hepatitis could be kept under control. The Willowbrook research is described by Saul Krugman and Joan P. Giles in Viral Hepatitis: New Light on an Old Disease, 212 J.A.M.A. 1019-29 (1970). 
cases? These difficulties are much less pronounced when we are dealing with legal rights, rather than with moral rights, which are not embodied in written laws. Moral philosophy addresses itself to such problems and issues, but has produced no universally applicable answer in all the years of debate. We believe, therefore, that knotty moral problems are not simplified by being couched in terms of people's rights, though it does not follow that talk about rights or appeals to rights ought to be eliminated entirely from our moral discourse. Since a good deal of ethical philosophy and many of our ordinary moral sensibilities and convictions are concerned with the basic rights of persons, we may still recognize the legitimacy of the notion of rights even if that notion is hard to understand fully and difficult to apply.

It is important to provide a clear analysis and explication of all of the ethical concepts we have discussed in this section, so that we can develop criteria that are useful and applicable in practice when informed consent must be obtained. It may be that some paternalistic acts are justifiable in experimental contexts, while others are not. We may decide that our fundamental ethical principles preclude the introduction of any coercive elements into the selection of experimental subjects or the attempt to gain their consent. Without careful analysis, we risk making our practical criteria too weak or too strong, too vague or too ambiguous, and therefore, inappropriate or difficult to apply.

\section{Theory and Practice}

Let us turn now to the specific ethical questions arising from the practice of experimenting on human subjects: (1) What experiments can be morally justified? and (2) Under what constraints should subjects be selected? In the account that follows, we shall show how one might obtain reasoned answers to these questions by using the philosophical theories and conceptual analyses sketched above.

In answering these questions, it makes a great deal of difference which ethical theory we choose to adopt. The theories of Kant and Mill are substantively different, and in some cases they yield different answers to moral questions. We must, therefore, weigh the options carefully and examine the consequences of adopting either theory. Once committed to a theory, we should try to be consistent and avoid appealing to our chosen theory only when its directives 
suit us, while choosing some alternative conception when they do not.

At first glance, it would seem that the acceptance of Kant's account requires that we consider all experiments using human subjects as wrong: experimenters necessarily use their subjects as means, since the subjects are, in a sense, instruments in the experiment. A closer look, however, shows that Kant's imperative is to treat persons as ends and not as means merely. It is permissible to treat persons as means, provided that we also consider them as ends.

Unfortunately, the language of "means" and "ends" is very conconfusing, and Kant does little to illuminate the matter. It is clear, though, that he cannot be enjoining us from ever using other persons to further our own ends. We treat persons as means when we hire them to move our furniture, cut our hair, treat our illnesses, and draw up contracts for us. It is a fact of life in any social environment that we treat people as means; in fact, it is generally believed that the chief purpose of societies is for people to band together to meet each other's needs in the most efficient way. ${ }^{33}$ Kant's injunction, therefore, cannot be construed as prohibiting any use whatsoever of another person for our own purpose. Rather, it prescribes that we not treat a person exclusively as a means. We must also attend to the individual's chosen ends and avoid using the person to meet our ends, unless by doing so we are contributing to the attainment of his own chosen ends.

With respect to experimentation, Kant would surely approve of those experiments in which an intended or hoped-for aim is some benefit to the subjects themselves. If an experiment is conducted both as a therapeutic attempt and to help others or to further knowledge, it is acceptable by this standard. Even if the subjects do not themselves need this treatment but merely have an interest in the success of the research for some other reason (for example, if the research is investigating an illness from which a relative suffers, or the subjects have a scientific curiosity about the matter, or, simply, are acting altruistically), the experiment would still be acceptable.

Nonetheless, Kant would find even these experiments unjustifiable if they could result in a reduction of an individual's ability to function as an independent, autonomous, rational agent. Rationality and autonomy are the most important human characteristics,

33. One of the earliest statements of this view appears in PLATO, THE REPUBLIC, Book II, 367e-372a (F. Cornford transl. Oxford Univ. 1945). 
and, as we noted earlier, they form the basis of our moral framework. Any act that might reduce these capacities would violate an important standard of human dignity and would be inconsistent with the third formulation of the categorical imperative. ${ }^{34}$ By this standard, all forms of novel exploratory experimentation on ways of effecting behavior change in humans would be suspect, be they behavior modification techniques, psychosurgery, or new chemical or electrical stimuli to the brain. The notorious syphilis experiment done at the Tuskegee Institute, ${ }^{35}$ in which unwitting subjects suffering from syphilis were left untreated for more than thirty years, was immoral according to Kant's criterion because it was known that many subjects would become mad in the stage of tertiary syphilis, and it is morally wrong to bring about or promote irrationality.

Kant also argues that being alive must be a fundamental value for everyone. Most people naturally choose life over death. For those who do not, Kant offers arguments to show that everyone who is able to choose has an obligation not to terminate his own life. It follows that others must respect this universally binding human end and that any experiment involving the death (or even a serious likelihood of death) of its subjects is wrong. Hence, even if the subjects are willing to risk their lives for the sake of the experiment, they are mistaken, for they ought to value their lives above most other considerations. It is wrong for anyone to violate this fundamental end. The only possible exceptions to the presumption against experiments involving death would be those cases in which death is imminent without the experiment, or where life is otherwise seriously threatened, say, by a high probability of contracting some fatal disease; but even then it would be right for subjects only to agree to a risk of death, while still refusing to allow certain death in the cause of science.

There is another whole set of experiments that Kant would object to: those involving deception. His ethical theory requires persons to act only in accordance with maxims that they could consistently will to be universal law. It appears to be clear to Kant that truth-telling fulfills this criterion while lying does not; thus it is always wrong to lie. Hence, any experiment that involves deliberate lying could not be justified in spite of its potential benefits. This is-

34. See note 18 supra and accompanying text.

35. See Hearings on S. 2071, S. 2072, and H.R. 7724 Before the Subcomm. on Health of the Senate Comm. on Labor and Public Welfare, 93d Cong., 1st Sess., pt. 4, at 1187-1253 (1973). 
sue is especially pertinent in the social sciences, where a great deal of research is conducted by means of deceptive experiments. The most famous of the genre is one run by Stanley Milgram in the mid1960 's, in which he investigated the degree to which persons will respond to authority. ${ }^{36}$ The procedure involved telling subjects that they were to administer painful and even fatal electric shocks to other volunteers on direction from an experimenter. The supposed recipient of the shock was actually a stooge, who cried out and made other appropriate responses on signal, but suffered no ill effects. Since it was important to the study that the subjects believed themselves to be actually adminstering shocks, and since 65 percent of the subjects administered what would have been fatal shocks, it was obviously ethically preferable to use deception. The only alternative (except not experimenting at all) would have been to administer killing dosages of shock. Nevertheless, a Kantian would not approve of this procedure, but would claim that lying in itself is wrong and cannot be made right by the goodness of its consequences. If the only way that this sort of experiment could have been conducted without lying would have been by killing people, then the experiment was unjustifiable in any form and should not have been conducted.

The utilitarian answer to the question of what experiments are morally justifiable is much easier to formulate, though surely no easier to apply. The utilitarian principle requires us to act in the way that produces the greatest general balance of happiness over unhappiness. In order to determine whether an experiment is justified, a utilitarian must calculate the "expected utility," that is, the good or happiness or welfare likely to come of it. The calculation proceeds by estimating the amount of happiness and multiplying that amount by the probability of its coming about as a result of this experiment, thereby obtaining a measure of the benefit at stake. The utilitarian must then weigh that benefit against the anticipated risk, determined by multiplying the amount of harm by the probability of its occurrence. The measure is complex, for it must include all the possible good and bad effects of the experiment-including feelings engendered in the general population, feelings of satisfaction or guilt on the part of participants, and consequences of actions done as a direct result of the experiment. However complex the utilitarian calculation may be, something very much like it ap- 
pears to be the underlying moral principle in the notion of the risk-benefit equation, as mentioned earlier. ${ }^{37}$

There is an obvious problem here for both Kantians and utilitarians. By the very nature of experimentation, research contexts often make possible studies for which the results are as yet unknown. Kant's principle refuses to permit experiments that will result in decreased autonomy on the part of the subject; Mill's principle allows only experiments that produce the greatest balance of good over evil in terms of pleasurable or painful consequences. The problem that confronts the prospective experimenter, then, lies in the fact that we cannot accurately predict the results. Inability to predict results does not, however, grant a license to act in total disregard of consequences (as, for example, in radically innovative experimental attempts). Instead, this unfortunate feature demands a strong responsibility on the part of researchers to study as best they can the possible or likely results and requires them to engage only in those tests with human subjects in which the experimenters are assured that there is little chance of significant harm to the subjects. Mistakes might still be made, just as mistakes are made in all other areas of human activity, but if researchers have sincerely tried to reduce the likelihood of risk and have not attempted an experiment when they have reason to believe serious harm may result, then they are justified in performing it.

Utilitarianism permits a wide range of experiments that Kantians would never consider. For instance, utilitarians would probably approve an experiment expected to provide a cure for cancer, even though it was expected to cause its early subjects to develop untreatable cancer; Kantians would surely object. Utilitarians as well as Kantians would object to the Tuskegee syphilis experiments, but on different grounds: Whereas Kantians would object to the loss of the subjects' autonomy as a result of illness and possible insanity, the utilitarians would object because the experiments did little good. If the experiments had been better designed and were likely to succeed in producing some significant, useful knowledge leading to beneficial results for humanity, utilitarians might be willing to approve, despite the resulting illness and insanity generated by the tests.

Still, utilitarians do not operate with a simple risk-benefit table that approves any experiment whatsoever where benefit measures highest. They are obliged to choose the option with the best ratio

37. Text accompanying note 11 supra. 
of benefit to risk, and so they have a strong responsibility to minimize risks. It is important to investigate alternative courses of action that might further improve the ratio, even if the benefit already outweighs the risk. In practice, this requirement would prevent Mill and most utilitarians from engaging in many experiments that are threatening to life or that interfere with the basic rights of persons. $^{38}$ If a great risk is present, utilitarians would generally assume that the experimenter should wait before performing this particular test and seek a safer means of obtaining the result. However, if no safe alternative can be devised, and if the expected benefit clearly outweighs the risk, in terms of happiness or well-being and pain or suffering, then utilitarians are obliged to permit experiments that Kantians would unconditionally oppose.

According to either conception of ethics, we can identify some types of experiments that are morally wrong; even if it were possible to obtain willing volunteers for such experiments, it would be wrong to perform them according to the fundamental moral principles of these theories. However, this analysis does not completely resolve our ethical questions because there are further moral conditions to be met even within the range of experiments that are not unjustifiable in principle. In general, these further considerations have to do with some conception of the individuals involved as experimental subjects. In the Kantian framework, human beings are thought to be autonomous creatures having dignity, and, hence, deserving respect. According to Mill, human beings are happier if they are treated with dignity and respect and if their personal freedom is made as extensive as is socially feasible. ${ }^{39}$ The difference between these two views in this regard lies in the ultimate end each theory posits. For Mill, pleasure or happiness is the ultimate end for man, so all actions must promote that end; for Kant, the only thing good in itself is a good will-a will whose motive for actions is that they be done for the sake of duty. In any case, it follows from either theory that we have a prima facie obligation to treat other persons

38. Mill claims that the moral agent must assure himself that in benefiting some persons by his actions "he is not violating the rights, that is, the legitimate and authorized expectations, of anyone else." J.S. MiLL, supra note 4, at 25 .

39. Mill refers to "the love of liberty and personal independence" in man, and to "a sense of dignity, which all human beings possess in one form or other, and in some, though by no means in exact, proportion to their bigher faculties, and which is so essential a part of the happiness of those in whom it is strong that nothing which conflicts with it could be otherwise than momentarily an object of desire to them." Id. at 13. 
honestly, to seek their consent in matters affecting them, and to be sensitive to their interests. The most effective way to attain these goals when dealing with subjects of experimentation is by obtaining their informed consent for all that we do with them.

In practice, such obligations are more easily fulfilled with certain groups of subjects than with others, thus it may be that while an experiment is permissible if done with one set of subjects, it is impermissible if done with some other group of subjects. As we have stressed, the ideal situation is one in which the experimental subjects are fully rational persons who have offered genuinely informed, voluntary consent. Under such conditions, there is considerable assurance that the researchers are not using the subjects solely as means. We cannot justify using persons as subjects of experiments against their will. If they actively resist participation, using them would violate Kant's prescription not to treat persons as mere means; Mill, too, would consider this an unjustified interference with the basic rights of persons. Thus, it is wrong to coerce people into serving as subjects when they have decided otherwise. It follows, then, that any coercive use of prisoners in experimentation is wrong.

The need for informed consent is a most difficult requirement, since it is common for research to deal exclusively with a condition only experienced by "dependent persons"-those not clearly capable or clearly incapable of providing informed consent. Medical researchers cannot investigate all the problems of prenatal injury without experimenting on fetuses, nor can medical or social scientists gain an understanding of the workings of Down's syndrome (mongolism) without experimenting on some of its victims. Psycho-pharmacologists must surely use psychotic patients to develop effective antipsychotic drugs, and gerontologists can only understand senility by conducting research on the senile. Obviously, the list could be extended to cover every class of persons limited by some medical or psychological condition. ${ }^{40}$ The potential benefits are great; the risks may be small. In so many cases the only hope of reducing suffering involves using persons who are unable to provide informed consent. Our problem is to decide when, if ever, we are justified in conducting an experiment without obtaining informed consent.

40. One class which has posed great difficulty for drug researchers is children. Because of the controversy over whether or not a child can give informed consent, "investigators are becoming progressively more reluctant to test new drugs in children." Cowan, supra note 2 , at 557. 
Utilitarians have no serious problem in these cases. There is a genuine disutility in allowing the practice of treating people as experimental subjects without their consent. Consider, as an extreme example, the wide-scale discomfort and anxiety experienced even to this day as a result of experiments performed by the Nazis. As a mere practical consideration the full cooperation of subjects, which can be expected after their consent has been obtained, should result in the greater success of many experiments. Still, there are times when we would be scientifically better off without worrying about informed consent. ${ }^{41}$ In such cases if we instituted some special experimental constraints with the aim of reducing anxiety about the possibility of Nazi-like atrocities, such experiments would be in accord with the utilitarian principle; hence, it would be justifiable on that theory to use subjects without their consent. In fact, utilitarianism seems to mandate the use of subjects with limited abilities whenever possible. Since such subjects are less likely to benefit society in other ways than are normal persons, it is in the social interest to take risks with their lives rather than with the lives of those fully rational persons who may make some other sort of contribution. Moreover, there is reason to believe that at least some of these individuals actually suffer less than others, or have less potential for happiness (e.g., fetuses, the severely retarded, the dying who are already suffering). If this is so, and if the general aim is to maximize the balance of happiness over pain in society, then there are further grounds for using these sorts of persons as experimental subjects.

It appears that we are now caught between extremes on the problem of experimentation: Kant's position is so rigid it seems implausibly strong, while the utilitarian solution seems almost heartless and inadequate to account for all our moral sensibilities. As a way out of this impasse, we shall introduce a line of reasoning developed by John Rawls and spelled out in detail in his book, $A$ Theory of Justice. ${ }^{42}$ Rawls works out an alternative conception of morality, which appeals to the insights of both of his predecessors.

Rawls is dissatisfied with the utilitarian approach, for it fails to account adequately for that element of justice commonly conceived as fairness. Two examples, one hypothetical and the other histori-

41. Dr. Cowan cites as one example of such a situation the "double blind trial" in drug studies, wherein it is crucial to keep the subjects ignorant of the nature of the drug being tested on them. Such ignorance would, of course, preclude the giving of fully informed consent. Cowan, supra note 2, at 55455.

42. J. RAwLs, supra note 10. 
cal, serve to illustrate this failure: If it would help in understanding and eventually curing depression to stimulate a person's brain with electrodes in order to produce in him a permanent, incapacitating state of depression that could be carefully studied and recorded until death, utilitarians would consent to the study. If they were convinced that the experiments would be useful, utilitarians would also be likely to allow the cancer study Southam and Levin performed on the unaware, aged inmates of the Jewish Chronic Disease Hospital, in which cancer cells were injected under their skin. ${ }^{43}$ In objecting to these features of the utilitarian moral theory, Rawls observes that "there is no reason in principle why the greater good of some should not compensate for the lesser losses of others; or more importantly, why the violation of the liberty of a few might not be made right by greater good shared by many."44 Rawls believes however that many people would charge such measures with being unfair, and justifiably so; unlike the utilitarians, he believes this would be a morally relevant objection. ${ }^{45} \mathrm{He}$ agrees that our ethical considerations ought to account for the general welfare, but he argues that they must also be concerned with justice, as well. ${ }^{46}$ It is not sufficient to worry only about maximizing happiness and minimizing pain.

In order to convey what is involved in determining a just solution, Rawls uses a thought experiment commonly appealed to in the literature of social and political philosophy. He asks us to imagine what a group of persons in a carefully defined original position would agree to if they were deciding amongst themselves on their social organization. ${ }^{47}$ Such a thought experiment is key to all social contract theories; 48 the important feature of any social contract is that everyone enter it willingly, that it be the sort of commitment all could agree to. Rawls uses this technique because he believes that a just procedure is one that does not take advantage of anyone but

43. See note 29 supra.

44. J. RAwLS, supra note 10 , at 26.

45. Id. passim (especially at 3-4).

46. Id. at 4-5.

47. Id. at 11-22.

48. The most prominent examples of such theories are, of course, those of Hobbes, Locke, and Rousseau. The terms of the contracts envisioned by these theories are not all the same; they arise out of the details of whichever original position the particular social contract theorist assumes. See T. Hobbes, Leviathan; J. Locke, Of Civil Government; J. Rousseau, The SoCial CONTRact. 
rather, allows everyone equality-a truly fair arrangement. 49 Such equality does not exist in real life, for actual social contracts are entered into by parties who are most concerned with fostering their own interests. Those with power are able to influence others and ensure a contract which, instead of being fair, unjustly supports the interests of the powerful at the expense of the weak. So the need arises for a thought experiment, and Rawls asks us to imagine a situation in which we have to agree on a standard of justice to apply to all future arrangements, without being able to account for our particular interests.

To construct this hypothetical situation Rawls directs us to imagine ourselves under a "veil of ignorance," who whereby we do not know any specific facts about ourselves: neither our wealth, social position, talents, preferences, age, nor race. We would know only the general facts of human nature on which Mill based his notion of a person's rights: that humans are sentient, that they are concerned with their own well-being, that they function in a society, and that their happiness depends upon fulfilling a certain life plan. Rawls argues that anyone making a decision under this constraint would have to act fairly, and deliberately avoid exploiting anyone, because it is possible that the decisionmaker might turn out to be the one exploited. The decisionmaker under the veil of ignorance will be most concerned with protecting himself from the worst fate. As a result, not knowing precisely who he himself is prior to the lifting of the veil of ignorance, he will have to act so as to protect everyone from such a fate. Hence, no one will be exploited or taken advantage of by using such a procedure. Everyone commits himself in advance to the system that is most fair.

While this is clearly an impractical suggestion since no one can block out all particular knowledge about himself, it is a valuable exercise nonetheless. Rawls does not expect us to experience literally the veil of ignorance. The situation is described in an attempt to capture our intuitions of what it would be like to act genuinely fairly, to be in a fully equal position where we would treat all alike and not favor ourselves. ${ }^{51}$ In doing so, we can secure the aim Kant had in mind in the first formulation of the categorical imperative, where he requires us to question whether the maxim of our action could consistently be adopted as a universal law. ${ }^{52}$

49. J. RAWLs, supra note 10 , at 12.

50. Id. at 12, 136-42.

51. See id. at 18-19.

52. See note 15 supra and accompanying text. 
Rawls uses the above-described conception to help formulate the principles of justice that he believes appropriate for evaluating the major institutions of society. ${ }^{53} \mathrm{He}$ argues that if persons were constrained in such a manner that rendered them all equal, they would adopt two principles of justice, which can be roughly stated as follows: (1) Everyone is entitled to the greatest equal liberty compatible with a like liberty for all; and (2) Inequalities are to be arranged so that they benefit the least advantaged and that positions associated with such inequalities are open to all. Further, these principles are ordered, so that no consideration-not even the satisfaction of the second principle-can justify depriving someone of a liberty open to others.

Rawls' theory provides us with a standard of justice by which to evaluate social institutions. There are other criteria that a society must also fulfill in order to be considered good. It should, for example, be efficient, productive, and conducive to happiness. But the criterion of justice is primary and inviolable; it cannot be overridden by utilitarian considerations.

Applying these precepts in the context of experimentation, we may note first that Rawls' theory, like Kant's, rejects some experiments in principle no matter what benefit might be gained from them. In particular, Rawls would judge impermissible all experiments that violate a liberty to which a person is entitled. Any experiment that might deprive its subjects of freedom of thought, freedom of the person, civil liberties, and political liberty, would be wrong under his conception. No experiment likely to render its subjects unable to act as autonomous, independent beings could be approved. Going even beyond Kant, Rawls would protect purely social or political liberties-those that are not natural products of an autonomous will but, rather, arise out of particular social constitutions that define and legitimize such rights.

As an example of experimentation that would call into play Rawls' concepts, consider some possible uses of electric shock. Aversion therapy with electric shocks has been used to control "compulsive gambling, homosexuality, compulsive eating, ... writer's cramp, ... habitual blushing, ... and marital infidelity."54 Presumably, some social scientists are curious to know whether such techniques might enable us to destroy motivation to vote, to form social bonds, or even to speak, in order that they

53. J. RAWLS, supra note 10 , at 302-03.

54. J. KATZ, supra note 29 , at 445. 
may discover how essential and ingrained these needs are in the human makeup. According to the Rawlsian conception of ethics, however, it would be wrong to conduct all such experiments.

The second principle of justice would prohibit taking advantage of the sick for the sake of others' well-being. An unequal distribution of risks, like other unequal distributions, can be justified only if it benefits those who are currently disadvantaged. Experiments that are therapeutic and may benefit their subjects, as well as help protect the medically well-off, would meet this requirement. However, experiments that are designed to help persons other than their subjects, and may in fact harm the subjects, are not permissible if the subjects are already worse off than the beneficiaries. Hence, Rawls would not approve of the Southam and Levin cancer study at the Jewish Chronic Disease Hospital, nor would he approve of any study using dying persons for the interests of others where the research did not also benefit its subjects. Similarly, he would disapprove of the use of retarded persons as subjects in experiments that were not directly related to their condition. If the Willowbrook study done by Saul Krugman were conceived of as an attempt to infect inmates of an institution with hepatitis virus in order to develop a vaccine useful to others, it too would fail the test. However, Krugman argues that the participants in this experiment were certain to contract the disease anyway, and so they were not made worse off but rather were benefited by the careful attention the experiment provided. ${ }^{55}$ If this assessment is correct, the experiment seems to satisfy this condition of justice. However, it could be argued that the fully competent, rational staff members at Willowbrook were in the same position with respect to contracting hepatitis and could just as well have been used as experimental subjects. If there were another option of choosing subjects who could also be selected without inflicting undue harm, it would have been preferable to use those who could provide informed consent. Experiments without informed consent are always to be viewed as a last resort. In general, however, the second principle of Rawls' theory of justice appears to preclude the use of institutionalized persons in experiments that threaten their well-being, since all such persons are appropriately viewed as disadvantaged.

According to Rawls then, it is unjust to use dependent persons as subjects for experiments unrelated to their condition. It is wrong to take advantage of their limited rationality and diminished ca-

55. Krugman \& Giles, supra note 32, at 1018-29. 
pacities in order to serve the ends of others. However, there is still the problem of experimental research that investigates the very conditions with which such persons are afflicted. For example, since the effects of drugs may differ considerably in infants and in adults, how could the effects of new drugs on infants ever be established, if experiments on infants are prohibited? ${ }^{56}$

Rawls' principles do not give us clear guidance on this issue, but by following his line of reasoning as a model we can gain a more specific understanding of our responsibilities toward dependent persons, as well as some direction concerning how they ought to be treated with regard to experimentation. Rawls claims that the just solution is always one to which everyone could agree in advance. ${ }^{57}$ Some medical conditions even provide a realistic framework for using the assumption of the relevant veil of ignorance, since we do not know in advance which of us will be victims of many diseases. Thus it is reasonable to assume that a fair procedure for selecting subjects for medical and psychological research in such cases is one upon which we can now agree without knowing our personal connection to the disease. It is, for instance, in the interest of all potential sufferers of heart disease to agree to undergo some discomfort for the sake of a study that might help eradicate the disease. Even without assuming any altruistic motives in people, it is reasonable to expect them to be willing to agree to such a procedure simply because they wish to protect themselves from developing untreatable heart disease. By the same token, people might also be expected to agree to participate in certain studies aimed at reducing the ill effects of the disease in those who are victimized by it. Since it is rational for all concerned to agree to experiments without undue risk, we can conclude that persons should all be willing to provide informed consent when called upon to participate. Relying on the sense of justice of those whose participation is needed, however, it is appropriate to insist upon informed consent in such cases,

\section{Stated simply:}

[O]ne cannot use new drugs in children unless they have been certified for use in children. But one cannot get new drugs certified for use in children because it is nonbeneficial research and one cannot do nonbeneficial research in children. Hence, either the pediatricians practice illegally or the children become therapeutic orphans.

Cowan, supra note 2 at 557.

57. This view is implicit in $A$ Theory of Justice and is stated explicitly in Rawls, Justice as Fairness, 67 The PhILosophical Rev. 164, 171 (1958): "The idea is that everyone should be required to make in advance a firm commitment, which others also may reasonably be expected to make . . . ." 
and to reserve the right of refusal in keeping with the spirit of Rawls' first principle - the greatest liberty principle.

In experimenting on persons with Down's syndrome we cannot employ directly analogous reasoning because the veil of ignorance is no longer real (though many can assume it in contemplating bearing such a child). Still, using Rawls' model we can try to determine what we would agree to if we took seriously the possibility that we might be affected by the condition. What research on both healthy and afflicted children would we agree to, in the interest of curing or treating Down's syndrome, if we seriously expected to be subjects of such research ourselves? What risks or suffering would we agree to in the interest of minimizing the severity and incidence of this condition? We need not actually experience the condition in order to address this question, any more than we have to be the worst off member of society to recognize the rightness of Rawls' principles of justice. We must simply try, so far as we are able, to determine what it would be like to have Down's syndrome.

Such an approach is significantly different from Kant's proposed method of accounting for everyone. Kant recommended that we treat every human being the same, qua member of the human species. $^{58}$ All persons were assumed to be entitled to the same treatment by virtue of belonging to a rational species. In contrast, Rawls' procedure licenses treating people differently according to their special interests. Kant takes the Golden Rule literally, advising us to do to others as we would want them to do to us. Rawls modifies it by recommending that we do to others as we would want them to do to us if we were they. ${ }^{59}$ While we might not want to have brain surgery done on us now, we might be willing and eager to have it done if we were suffering violent headaches that might be alleviated by surgery; we might even decide now that we want it done in the event we were ever to suffer such headaches, even if at that later point we were too irrational to agree to it. Similarly, although we would not want to be institutionalized during a present state of full mental capacity, if we were so severely retarded that we could not care for our own needs, we might well want to be institutionalized if we were capable of choosing.

In following Rawls' method, we must imagine what we would choose in various circumstances, knowing full well that if such conditions obtained, we would be incapable of rational choice. This

58. See discussion of Kant in text following notes 11 and 21 supra.

59. J. RAwLs, supra note 10, passim (especially at 95-108). 
reasoning justifies paternalism in cases involving persons who are not fully rational, for rational agents would want to insure themselves against any situation in which they might lack the power to pursue their own interest. In the original position, "the parties adopt principles stipulating when others are authorized to act in their behalf and to override their present wishes if necessary; and this they do recognizing that sometimes their capacity to act rationally for their good may fail, or be lacking altogether."60

Hence, while justice requires us to extend liberty as far as possible, it also provides for a cautious use of paternalism when an individual is not rational enough to care for his own interests. Such paternalism is justified by the fact that it is rational to choose to have someone behave paternalistically towards us should we become incapable of looking out for ourselves. Thus, all persons are likely to agree to such a practice, provided it includes carefully designed constraints prohibiting paternalism when persons are rational enough to decide for themselves.

If someone were called upon to make a paternalistic decision on our behalf, that person would be required "to do what we would do for ourselves if we were rational . . .."61 For ourselves, when contemplating a paternalistic action, "[a]s we know less and less about a person, we act for him as we would act for ourselves from the standpoint of the original position." 22

If the preceding account provides an acceptable model for morally justified paternalism, it follows that when a decision needs to be made on behalf of a dependent person whether or not he should participate in an experiment, the task is to determine whether it would be rational for anyone to agree from the position of the relevant veil of ignorance. Experiments with high risk or poor riskbenefit ratios would not pass this test, since it can be assumed that no rational agent in the original position would agree to be a participant. In other words, experiments must at least meet rigid utilitarian standards to be approved by this method; but they must not bear too high a cost for any particular individual.

According to Rawls' theory, the researcher is always in a better moral position when he has obtained genuinely informed consent; having gained consent, the experimenter is most assured of acting in accordance with what the experimental subject himself could

60. Id. at 249.

61. Id.

62. Id. 
agree to. Further, the second principle of justice urges that hardships be distributed in a manner that serves the interests of the disadvantaged. Since it is reasonable to hold that persons who are not fully rational are disadvantaged by virtue of their diminished capacities, it seems clear that they should not be made to suffer any further for the sake of people who are more advantaged.

If, therefore, the use of human beings as experimental subjects can be justified at all, it is best to choose those who have provided informed consent rather than those who have not. An example of a wholly unjustifiable experiment is one performed in 1949 to investigate the possibility of toxic effects from agene, a substance used in the manufacture of flour. ${ }^{63}$ There had previously been many reports of its toxic effects on animals and there was a desire to know if it was also toxic for humans. Thus, eighty boys, whose ages ranged from 10 to 15 years, were chosen from a residential school, and all were fed agenized flour for 6 months. When no ill effects developed, two adults were put on agenized flour for 6 weeks. Surely, if the experiment had to be conducted at all, it could have begun with adult volunteers-perhaps, the experimenters themselves.

If there is no alternative but to use subjects who cannot provide informed consent, and if the experiment is warranted in terms of its risk-benefit ratio, then a third party has a right to consent on behalf of the subject only if (1) the decisionmaker has good reason to believe it is a decision the person would in fact make if he were rational, or (2) lacking such information, it is in accordance with a decision any rational person would make knowing he might be in the subject's place. On this model, the paternalistic decisionmaker must ask: "Would it be rational for me to agree if I were he?"

In concluding this section, we turn to a distinctive range of moral problems arising in connection with a special class of persons whose use in experimentation has occasioned much debate. We refer, of course, to prisoners, whose circumstances give rise to a unique sort of dilemma. Prison conditions are such that the freedom of prisoners is severely restricted in ways that render them susceptible to various forms of coercion. Moreover, some members of our society clearly seem ito value the lives of prisoners less than the lives of others; in Kantian terminology, prisoners are sometimes perceived as possessing less dignity and, as a result, are viewed as

63. See Elithorn, Johnson \& Crosskey, Effects of Agenised Flour on Man, The LaNCeT, Jan. 22, 1949, at 143. 
less deserving of respect. Such an attitude requires justification before it can be incorporated into any moral arguments, and it surely cannot be justified within the scope of Kant's theory. It is, nevertheless, an attitude that some people have and are prepared to act on. Because of these circumstances it is important to guarantee the prohibition of any coercive use of prisoners in experiments.

However, there is a further problem with using prisoners as exexperimental subjects-a problem that is related to the unusual circumstances inherent in a prisoner's situation. It is sometimes argued that the prison environment actually distorts the needs and desires of its inmates to a point where prisoners are no longer fully capable of accurately identifying their own interests. ${ }^{64}$ For instance, in prison a dollar assumes a value very much out of proportion to its normal worth, for the ability to purchase cigarettes or chocolates becomes a matter of paramount importance to those allowed little opportunity to make choices. ${ }^{65}$ Even this small sum may appear to be of such importance that the prisoner will sacrifice what others perceive to be his genuine well-being in pursuit of it. Under these circumstances, it is quite easy for someone who does not so value that dollar to get prisoners to take risks to which a rational agent in a natural social setting would never agree. Experimenters are in a position to take advantage of this unfortunate situation and any resultant nonrational preferences of prisoners.

If the judgment is correct that prisoners are responding inappropriately to options presented-that they are neglecting their overall well-being for the sake of lesser ends-then there is reason to believe that we cannot consider their consent to participate in experiments as legitimate, even if they have been fully informed about the details of the experiment. It would seem that prisoners themselves may mistakenly identify their own ends; they may act in ways that bring about a reduction in their own well-being. Now, it is true that we all do this to some extent, but the point is that an identifiable pattern seems to exist according to which many persons appear to lose perspective on their interests in similar ways under prison conditions. ${ }^{66}$ Such uniformity allows us to specify the particular areas in which their surroundings decrease the ability of prisoners to make rational decisions.

Nevertheless, it may be the case that inmates' interests are genu-

64. See Mitford, supra note 31, at 64-73.

65. Id.

66. Cf. M. Pappworth, Human Guinea Pigs 63-68 (1967). 
inely changed in the prison environment and, as a result, such prisoners are not misperceiving their ends or acting irrationally. A proper evaluation of this issue will require a complex, well-confirmed theory of human ends of a sort not currently provided by psychology or the social sciences generally. But if we suspect that prisoners' preferences have become inappropriately distorted, and, further, if in applying Rawls' test we decide that we would not want to be in circumstances leading us to reorder our current values if we were to find ourselves in prison, then we are obliged to protect prisoners from making agreements we fear might be irrational. For example, the current practice of using prisoners in the first phase of drug-testing on humans ${ }^{67}$ seems to reflect an assumption that no free, rational person would agree to be among the first human beings subjected to the drug. If this assumption is true, Rawls' model yields the conclusion that this use of prisoners is unwarranted.

Kant insists that we respect a person's ends if ever we use him as a means. If prison renders some persons incapable of accurately perceiving their ends, an experimenter who responds to their mistakenly identified ends would fail to satisfy Kant's imperative. Experimenters who obtain subjects by meeting prisoners' mistakenly chosen ends-who actively take advantage of this confusion-are treating these persons as means and not as ends. However, there are some experiments that do address the prisoner-subjects' legitimate ends, be they a sense of altruism, a chance of parole, or even minimal monetary reward. Such experiments could then be justified, provided they also meet the requirements for informed consent as discussed above: the prisoner-subject's decision to participate must be a rational choice for him to make under the circumstances, and, further, the options open to him should be such that his consent can be considered wholly voluntary in the relevant respect; that is, it must be uncoerced.

\section{CONCLUSION}

In providing a theoretical framework for analyzing the moral dilemmas that arise in human experimentation, ${ }^{68}$ we have exam-

67. See id. at $62,65,67$; ExperIMENTATION with HuMAN BeIngs, supra note 29 , at $1041-49$.

68. There are some areas of concern that have been barely mentioned in this article. One large area is significant in much social scientific research: the use of deception. This technique causes special problems because it appears necessary to deceive the subjects in some experiments (especially in psychology) in order to investigate the topic under inquiry. But subjects who are deceived are not, by definition, informed, and so informed consent can never 
ined the issues involved in experimenting on human subjects from a number of philosophical perspectives. We began by looking at the fundamental questions concerning human experimentation as an acceptable moral practice: Why is there an ethical issue at all surrounding the use of humans in research? What characteristics do human beings have that set up presumptions against using people in experiments as we use inanimate objects or lower forms of life? ${ }^{69}$ We found that the characteristics of sentience and rationality in the human species are the properties that give rise to the need for ethical principles of a general sort, from which particular moral judgments flow, assessing the rightness or wrongness of any action.

The two major ethical traditions in modern Western philosophy, represented in turn by John Stuart Mill and Immanuel Kant, both have at their base a moral principle that emphasizes the intrinsic value or inherent worth of one or both of these fundamental attributes of humans. Sentience, conjoined with the related capacity for purposive or goal-directed behavior, and rationality, along with its derivative concepts of autonomy and the inherent dignity of humans, together comprise a framework for ethical judgments or moral decisionmaking in virtually any human context. As we saw,

be obtained in principle. When confronted with objections to deception in psychological experiments, some researchers known to these writers dismiss them as arising out of too rigid an adherence to ethical rules that prescribe truthtelling. If, however, we are justified in attaching significant moral value to the practice of obtaining fully informed, voluntary consent, then the simple reply based on truth-telling will not satisfy the serious objector to deception in social scientific research. Here, it would seem, the risk-benefit ratio assumes some importance since the experimenter is obliged to seek ways of conducting research without deception, so that the informed consent of his subjects can be obtained. Moreover, if he can find no experimental design compatible with obtaining genuinely informed consent, then the potential benefits of the experiment (or the research in general) must be objectively assessed in light of the fact that human beings are being used without their informed consent by a researcher as a means to his scientific ends.

There are other special problems of an ethical nature in social scientific research (e.g., maintaining confidentiality), and in still other areas of medicine there exist a variety of related issues, such as the use of untreated control groups in experimentation with new drugs or therapeutic procedures, and the widespread use of placebos in experimental therapeutic contexts. The sort of analysis offered in this paper can easily be extended to cover these related issues, and once equipped with one or more basic moral principles, which lie at the heart of a well-founded ethical theory, we can approach almost all special cases and new situations in which moral dilemmas occur.

69. The use of higher animals is, of course, the subject of much debate because such creatures more closely resemble humans in particular, relevant respects. 
the contemporary theory of justice propounded by John Rawls draws on elements from these and other philosophical traditions (e.g., the social contract theories) and proposes a pair of principles for evaluating institutions and social arrangements where justice is a concern. While it seems to us that Rawls' theory is superior in a a number of ways to those of Mill and Kant in its application to ethical issues in human experimentation, ultimately the choice of a basic moral principle is left to each individual. Rawls' account might provide a means of settling ethical disputes between, say, a utilitarian and a Kantian over what kind of research on human subjects is morally justifiable. As we have seen, actions that are morally permissible according to the utilitarian theory may be impermissible according to Kant. Rawls' conjectural method enables us to bypass dilemmas of this sort in seeking a just, fair solution to moral problems. His account is not problem-free, but it does seem significantly applicable to ethical issues in human experimentation.

Of course, the application of ethical theories to everyday, practical matters is not an easy task. In addition, conflicts of legitimate interest among persons and conflicts of fundamental principles will always arise, in the nature of human contingencies. The consistent, conscientious practice of morally justifiable behavior is difficult, as most people know by experience and observation. It is our hope that the philosophical perspectives presented in this paper will, at least, clarify and illuminate our thinking on a range of moral concerns we all share about experimentation on human subjects. 